\title{
Determinants of Web Search Effectiveness from the Perspective of Library and Information Science Students
}

\author{
Adeyinka Tella, University of Ilorin, Ilorin, Nigeria \\ (iD) https://orcid.org/0000-0002-5382-4471 \\ Saheed Oyeniran, University of Ilorin, Ilorin, Nigeria \\ Ebenezer Sanya Ibironke, University of Ilorin, Ilorin, Nigeria
}

\begin{abstract}
This study examined an empirical analysis of the determinants of library and information science students' web search effectiveness at the University of Ilorin, Nigeria. A total enumerative method was used where the entire 146 year three and four undergraduate students of the Department of Library and Information Science represent the sample. Through a survey approach, a questionnaire was developed and used for the collection of data. Three research questions were developed to guide the study. The results demonstrate that determinants such as internet and computer self-efficacy, information literacy skills, use of Boolean operators, and use of appropriate search terms significantly correlate with and determine web search effectiveness.
\end{abstract}

\section{KEYWORDS}

Computer Self-Efficacy, Information Literacy Skills, Information Retrieval, Information Searching, Internet Search, Internet Self-Efficacy, LIS Undergraduate, Web Search

\section{INTRODUCTION}

As more information is added and uploaded on various websites, the searching of such websites to satisfy academic information needs by undergraduate students generally, and library and information science undergraduates particularly, is on the increase. The emergence of the Internet has created millions of end users who search for information themselves as postulated by Xie (2010). Web search or information searching can be defined as users' purposive behaviour in finding relevant and useful information in their interactions with the information retrieval system (Knight, \& Spink, 2008). Searching and accessing relevant and comprehensive information is difficult because of the complexity in searching literature from various information resources especially from digital resources.

Web searching is now a common phenomenon among undergraduate students. Most of these students now depend largely on web information resources to tackle given assignments and research. The Web has grown into a vital channel of communication and an important vehicle for information dissemination and retrieval, "which is exerting power over the evolution and development of information-seeking behaviour' (Martzoukou, 2005; Tella \& Oyegunle, 2016). The enormous amount of digital information accessible today poses a great challenge to information retrieval systems to

\section{DOI: 10.4018/IJLIS.20210701.oa13}

This article published as an Open Access article distributed under the terms of the Creative Commons Attribution License (http://creativecommons.org/licenses/by/4.0/) which permits unrestricted use, distribution, and production in any medium, provided the author of the original work and original publication source are properly credited. 
retrieve effectively the information the user needs. Within this dynamic and vastly diverse searching environment, information seeking behaviour studies, and traditional search systems are not able to provide mechanisms for rich information retrieval to users as compare to searching through the Web (Martzoukou, 2005).

Web searching services such as Google and Yahoo are now the search engines that people access every day to find information. Some studies that investigated such issues have recommended that Web search trends are important for both users and Web search engines alike (Florida Community College, 2018). User's Web search context can be examined at many levels, including the information environment/social level, organizational level, information seeking level, human-computer interaction level and query level (Spink \& Jensen, 2004). To understand better Web search effectiveness, there is need to understand the factors that promote or determine search effectiveness.

The Web has enabled users to electronically publish information and makes it accessible to millions of people with ease. However, as the quantity of this information grows, the ability of those people finding relevant materials decreased dramatically. Researchers (like Russell-Rose, 2011; Tella, 2011; Tella \& Oyedokun, 2014; Tella, et al. 2017; Khan, have shown a growing interest in the information-search activities of undergraduate students. These authors emphasised that people want information at the point they need them but don't bother about the necessary skills they need to develop to access the needed information. Students, when confronted with a decision-making situation (such as seeking for information to satisfy a need) they must decide when and where to search for information, when to rely on their own expertise or intuition, and when to rely on the advice of others. Time and resource constraints also undoubtedly influence their information-search activities, as well as the importance they place on different issues.

Web search activity and online information retrieval and information search studies through surveys, observations and experiments have been carried out (Moon, 2004; Kim, 2008, Lopes, 2016; Khan, 2018). In a comprehensive review of these studies, Malik and Mahmood (2009) and (Khan, 2018) concluded that research on web search activities and behaviour is still in the formative stage. However, Malik and Mahmood (2009) and (Khan, 2018) stated that it is not clear whether the factors influencing the search process, effectiveness or outcomes are understood well enough to be effectively studied in a cause-effect study. Studies have also examined web search activities and behaviour most of which generally focus on managers and students. However, limited studies have focused on web search behaviour among undergraduate students from a specific discipline such as Library and Information Science knowing full well that their training is all about assisting users in retrieving information from the information systems such as the web, the library or web electronic databases or social media platforms and how they themselves go about web search activities. As such, it is important to organise various factors identified in the literature by researchers to see how they determine web search effectiveness. This will provide a framework for integrating the results of previous studies and for guiding future researchers in their choice of research problems and variables so that their studies might form a cumulative body of knowledge. Considering this, the current study was designed to examine through empirical analysis the determinants of web search effectiveness among the LIS undergraduate students at the University of Ilorin, Nigeria.

\section{LITERATURE REVIEW}

Web search activity is the act of finding and search for information from the web and it is synonymous with browsing, sourcing, searching, navigating, seeking. This study adopts to use web search and browsing synonymously. Web search which Bates (2007) refers to as browsing is "the activity of engaging in a series of glimpses, each of which may or may not lead to closer examination of a (physical or represented) object, which may or may not lead to (physical and/or conceptual) acquisition of the object". Browsing provides an alternative strategy for locating information of the first kind and may provide one of the crucial ways for information of the second kind to be encountered. It is observed 
that much has been written on information search activities in Library and Information Science literature. It is on that note that Naughton (2016) argued that it is difficult to specify browsing based on three reasons. Firstly, the conditions under which browsing is used vary widely. Secondly, it seems to be rather unpredictable in its very nature and thirdly; it seems to be employed in both more and less directed, intentional ways. When comparing searching and browsing, Rice et al. (2001:177) indicated that the source in which browsing appears have been most comprehensively reviewed and discussed. Common definitions identified by Rice and others are in three categories: 1) directed browsing, 2) semi-directed or predictive browsing and 3) undirected browsing.

Consequent on the review of several definitions, (Rice et al., 2001:178) concluded that four dimensions have been most prominent. Browsing for instance embodies an act of scanning, which has been variously described as looking, examining, or sampling where the person's body or eyes move smoothly at will". This may be because of purpose or absence of a purpose. Premise on this, a purposeful act can be goal-directed or non-goal-directed; the presence of an intention suggests that the concept of browsing cannot be adequately described by behavioural characteristics alone" (p. 178). In furtherance to this, Booth (2016) explained that search criteria may be extensively, minimally, or not at all specified. Most of the time, the objective of browsing is well defined; at the other end, the objective of browsing is not defined" (p. 178). The browser's knowledge of the resource browsed either search paths in or contents of, can affect the quality of the interaction with the resource substantially (pp. 178-9). In this study therefore, web search is considered effective if the outcomes of the search meet the searchers' needs, with the expression of satisfaction.

There are many reasons or factors that make both access to and utilisation of the web both desirable and necessary. Its ubiquitous nature has deemed access to and familiarity with the Internet an assumption of the modern age; not using the net may even be socially undesirable, as suggested by Wolfinbarger, Gilly \& Schau (2005). Obviously, the human computer interface is becoming increasingly intuitive as inexperienced users are still having formidable problems coping with its use. The Internet has the potential to impact on many facets of daily lives, but for many people the ability to exert that power is limited by an inability to control that potential. Self-efficacy for technology use may be an important factor resulting in web search effectiveness.

In other words, there are other factors identified in the literature that can determine web search effectiveness. These include information literacy skills, internet self-efficacy, computer self-efficacy, emotional intelligence, participation in online discussion forum, knowledge of Boolean operators, and use of appropriate keywords. These are considered numerous to focus. In the light of this, five of these factors have been the focus in this study leaving the remaining ones for the future researchers. The ones focused are Internet Self-Efficacy, Computer Self-Efficacy, Information Literacy Skills, Use of Boolean operators and use of appropriate search terms. These five were chosen to be focused in this study because limited study have considered each or combination of them to determine web search effectiveness.

\section{Internet Self-Efficacy and Computer Self-Efficacy}

According to Cassidy and Eachus (1999), self-efficacy is an important factor in understanding the frequency and success with which individuals use computers. This can also apply to using and searching the web. Compeau, Higgins, and Huff (1999) tested the influence of computer self-efficacy beliefs, outcome expectations, affect, and anxiety on computer use, and found that computer self-efficacy beliefs had a significantly positive influence on computer use. In relation to this, the study expected that, internet and computer self-efficacy is should enhance or influence web search effectiveness. Relevant to the examination of self-efficacy and computer self-efficacy in relation to web search effectiveness, Tella, Anyim, Memudu and Olaniyi (2017) examined predictors of information retrieval effectiveness among Library and Information Science (LIS) undergraduate students in universities in Kwara State, Nigeria; considered correlation among the predictors of information retrieval effectiveness, identify the best predictive factor of information retrieval effectiveness, and the problems 
militating against information retrieval effectiveness. The results demonstrated that inter-correlation exist among the independent variables/factors and Information Retrieval Effectiveness; in addition, factors such as emotional intelligence, internet self-efficacy, and use of Boolean search operators significantly correlate with and predict information retrieval effectiveness. Similarly, computer selfefficacy has the highest predictive value compare to other variables while emotional intelligence has the least predictive value of information retrieval effectiveness. Based on the findings, the study recommend that LIS students should be more Computer self-efficacious so that they can be more effective in their information retrieval activities. It was also suggested that students should engage themselves in self-efficacy and computer training. The experience is assumed will go a long way assisting the students thereby enhance and facilitate their information retrieval activities.

\section{Information Literacy Skills}

One of the mandates of today's higher education is to develop a community of students with information literacy (IL) skills while pursuing their education and enable them to further extend it to their future workplace. Information literacy leads to lifelong learning (Lau, 2006) and is a common requirement to all learning environments, to all disciplines and to all levels of education. It helps the learners to master content, become self-sufficient and take greater control over their self-learning. "Information literacy is a set of abilities requiring individuals to recognize when information is needed and have the ability to locate, evaluate, and use effectively the needed information" (ACRL, 2000; Olaniyi, 2018). Similarly, information literacy is the ability to identify, evaluate, organize, and use the information judiciously (Syamalamba, 2011). The term information literacy encompasses a wide range of competencies acquired through a multiplicity of methods of library instruction focused on educating its users. They are variably known as information fluency, user education, library instruction, bibliographic instruction, information competencies, information skills, development of information skills (Tella, 2014).

In this era of information overload, information literacy is considered a valuable tool for students to become lifelong learners. Going by this, a user searching the web for information with good knowledge of information literacy will engage in effective web search and consequently satisfied with the outcomes. Chinyere (2014) found that the user education equipped the library users with the skills that enabled them to be independent in searching literature and helped them to retrieve needed information. Information literacy is a likeness of use education; therefore, it is expected in this study that information literacy skills possess by library and information science undergraduate will determine their web search effectiveness. Alhenshiri and Duffy (2010) provided technical support for research in Web Information Retrieval (Web IR). The main objective of the paper was to discuss experimental data, evaluation metrics, and results analysis in user studies intended for evaluating the effectiveness of web information retrieval techniques. User related measures are discussed in the light of emerging web search techniques. Indications for further improvements in web search evaluation studies were highlighted. Similarly, Xie (2010) provided an historic context to illustrate the evolution of the four main digital environments that users interact with in their search process to offer readers background information regarding the transition from manual information systems to computer-based information retrieval (IR) systems, as well as the transition from intermediary searching to end-user searching. Emphasis is placed on the review of different levels of information searching from search tactics/moves, search strategies, and usage patterns, to search models and associated factors in relation to task, user knowledge structure, IR system design, and social-organization context. Search models are further classified into two types, with one type illustrating information search process (ISP) and the other type emphasizing the factors that influence the process. In addition, unsolved problems and future research are discussed and suggested. 


\section{Use of Boolean Operators}

Boolean operators are a logical method of connecting search terms with AND, OR, and NOT (known as "Boolean Operators") to either narrow, expand, or exclude information in a search. Boolean searches allow you to combine words and phrases using the words AND, OR, NOT (otherwise known as Boolean operators) to limit, widen, or define your search (Collins, 2018). Given the overwhelming amount of information available on the Web and in online databases, Boolean operators can help focus a search, particularly when a topic contains multiple terms. Web searchers seldom use advanced query structure, such as Boolean operators or phrase searching, when using information retrieval (IR) systems (Borgman, 1996). Numerous Web studies note the near absence of query operators such as AND, OR, NOT, MUST APPEAR (+), and PHRASE (“") in Web queries (Spink, Jansen, Wolfram, \& Saracevic, 2002; Hölscher \& Strube, 2000). The use of Boolean operators is typically about $10 \%$ in these Web searching studies. It is generally assumed that the proper use of query operators would increase the effectiveness of Web searches. Similarly, retrieval effectiveness was associated positively with best-match searching and Use of Boolean operators in Web queries (Ford, Miller, \& Moss 2002) and Upstate Library (2018). On the contrary, Boolean and other operators in Web searching has little impact on the quality of assistance in the appropriate and effective use of query operators (Eastman $\&$ Jansen, 2004). Since more than two decades ago that Ford et al and others have examined the use of Boolean operators and how they enable search effectiveness, more development have taken place that call for the researchers to revisit the research. Not this alone, it is also observed that the research findings on the use of Boolean operator to experience effective Web search is mixed.

\section{Use of Appropriate Search Term/Information Retrieval Knowledge}

The key to engage in an effective web search is to use appropriate search terms and techniques that can be applied to most web search (Victor Valey College, 2018). Such will enable quick retrieval of relevant information without having to shift through thousands of unrelated links. In relation to information retrieval knowledge, IR knowledge assists users to develop conceptual and procedural strategies (Marchionini.; Dwiggins; Katz; Lin, 1993). No doubt, experienced users apply better strategies and perform better than novice users in the ISP (Howard, 1982). Many people have assumed that correct use of appropriate search term would increase the effectiveness of Web searches by increasing the total number of retrieved documents, increasing the number of relevant documents retrieved, or improving the ranking of relevant documents. It is the light of this that this study sought to find out if the use of appropriate search terms will determine web search effectiveness of LIS undergraduate students.

Russell-Rose and Chamberlain (2017) investigated the search behaviour of healthcare information professionals, uncovering their needs, goals, and requirements for information retrieval systems. A survey was distributed to healthcare information professionals via professional association email discussion lists. It investigated the search tasks they undertake, their techniques for search strategy formulation, their approaches to evaluating search results, and their preferred functionality for searching library-style databases. The popular literature search system PubMed was then evaluated to determine the extent to which their needs were met. The results revealed that 107 respondents indicated that their information retrieval process relied on the use of complex, repeatable, and transparent search strategies. The most desired features of a search system were merging search queries and combining search results. The study concluded that healthcare information professionals routinely address some of the most challenging information retrieval problems of any profession. However, their needs are not fully supported by current literature search systems and there is demand for improved functionality, regarding the development and management of search strategies. Similarly, Lewandoski (2015) compared five major Web search engines (Google, Yahoo, MSN, Ask.com, and Seekport) for their retrieval effectiveness, considering not only the results but also the results descriptions. The study used real-life queries and the results demonstrated that the two major search engines, Google and Yahoo, perform best, and there are no significant differences between them. Google delivers significantly more relevant result descriptions than any other search engine. This could be one reason for users 
perceiving this engine as superior. In terms of limitation, the study is based on a user model where the user considers a certain amount of results rather systematically. This may not be the case in real life. Practically, the results imply that search engines should focus on relevant descriptions. Searchers are advised to use other search engines in addition to Google. The study differs considerably from the current study because it focused on the comparative analysis of five different search engine and information retrieval effectiveness. This current study focuses on web search effectiveness arising from the outcomes of search activity engaged by the users using his skills and search strategies.

Lewandoski (2014) took a random representative sample of 1,000 informational and 1,000 navigational queries from a major German search engine and comparing Google's and Bing's results based on this sample. Data was collected using specialised software, the Relevance Assessment Tool (RAT). It was reported that while Google outperforms Bing in both query types, the difference in the performance for informational queries was rather low. However, for navigational queries, Google found the correct answer in $95.3 \%$ of cases whereas Bing only found the correct answer in $76.6 \%$ of the time. The study concluded that search engine performance on navigational queries is of great importance, as users in this case can clearly identify queries that have returned correct results. This study differs from the current study because it relied solely on the use of search engine for effective retrieval; whereas the currently study focus mainly of the users in terms of the skills he/she must embark of effective search on the web.

It is evident from the review of literature about particularly from the explorative aspects the five variables focused in this study have not been widely researched. In addition, studies on web search effectiveness that focused precisely on undergraduate students of a discipline have not been studied. In addition, studies of this kind in Africa that focus on undergraduate students of the Nigeria population is very scarce or not available. Considering this, the study examines through empirical analysis the determinants of web search effectiveness among the LIS undergraduate students at the University of Ilorin, Nigeria.

\section{METHODOLOGY}

\section{Design}

This study adopts a quantitative methodology using survey design. Survey design was chosen because it allows the researcher to draw a large sample that is representative of the total population (Babie, 2014). In other words, the essence was to be able to cover a substantial percentage of students in the department of Library and Information Science, University of Ilorin. Moreover, survey design was chosen because it is the most prominent approach used in previous related studies (Malik and Mahmood, 2011; Tella, 2013 Tella et al, 2017). And in addition, survey was adopted to enable generalisation and external validity of the findings of the study.

\section{Population and Sample}

The population of the study comprised of students in the department of Library and Information Science year 3 and 4 students in the Faculty of Communication and Information Sciences, the University of Ilorin, Nigeria. These group of register for and take courses on online information retrieval. Hence, they were considered as the good fit to supply the necessary data needed in this study. LIS department of the Faculty of Communication and Information Sciences, University of Ilorin was founded in the year 2008. Now, the department has students in year one, two and three and four and runs postgraduate programmes including masters and doctoral. However, students at postgraduate levels were not included in the study because course online information is not embedded in their curriculum. A total enumerative sample technique was embarked upon. This was to cover the entire population of students in both year 3 and years 4 of their study. The breakdown of the 
sample includes: Year Three $=75$ students, Year Four $=71$. This gives a total of 146 students which eventually represent the sample for the study.

\section{Instrument}

A self-designed questionnaire was used for data collection. The use of questionnaire for data collection is in line with the quantitative method was used in this study. The design of the questionnaire was informed by the objective and research questions focused in the study. Items in the questionnaire were adapted from previous related studies (e.g. Zhang, Anghelescu, and Yuan, 2005; Malik and Mahmood, 2009). The questionnaire was divided into two sections. Section A requires the respondents' demographic information including gender, year of study, and age. Section B contains the items. This is sub-divided into parts based on the objectives and research questions. The description of the parts goes thus: Part 1: Internet Self-Efficacy, Part 2: Computer Self-Efficacy; Part 3: Information Literacy Skills; Part 4: Use of Boolean Operators, Part 5, Use of Appropriate Search Terms and Knowledge of IR and Part 6, Web Search effectiveness. There are five items in each part. The response format followed five points Likert type ranges from Strongly Agree to Strongly Disagree.

\section{Validity and Reliability}

The instrument after its development was given to two experts with expertise in online information retrieval, internet/web search research. The suggestions and comments by the experts assisted in the moderation and modification of the items in the questionnaire. Moreover, most items in the instrument were adapted from previous related studies also justifies the validity of the instrument. To ensure the reliability of the questionnaire, it was administered on 20 students from a department outside the faculty of Communication and Information Sciences. A test-re-test reliability method of two weeks interval was employed, and responses collected were subjected to Cronbach alpha. The overall reliability of the questionnaire returned an $\mathrm{r}=0.93$ which exceed the minimum standard of 0.80 suggested for basic research (Creswell, 2014).

\section{Procedure of Administration}

The researcher personally administered the questionnaire to the respondents. The respondents were given voluntary opportunity to participate in the study while at the same time educated on the importance benefits of the research to them. Their informed consent was also sought before the administration of the instrument. The questionnaire was administered in 3 batches; with each level of study (year of study) constituting a batch. The exercise took three days. The entire 146 copies of questionnaires administered were returned filled representing $100 \%$ return rate. These were used for data analysis on the study. The study commenced in January 2018 and was completed in May 2018.

As evident from the above review of literature, much has not been done as far as identification of factors contributing or determining web search effectiveness is concerned particularly in the African context generally and Nigeria specifically. It is in the light of this that this study examines empirical analysis of web search effectiveness among Library and Information Science undergraduate students. To achieve this laudable objective, the following hypotheses were formulated and tested at 0.05 level of significance.

1. There is no significant correlation among the factors identified as determinants of web search effectiveness.

2. Internet Self-Efficacy, Computer Self-Efficacy; Information Literacy Skills; Use of Boolean Operators, Use of Appropriate Search Terms and Knowledge of IR will not significantly determine Web Search effectiveness.

3. Internet Self-Efficacy, Computer Self-Efficacy; Information Literacy Skills; Use of Boolean Operators, Use of Appropriate Search Terms and Knowledge of IR will not significantly contribute Web Search effectiveness. 
Table 1. Demographic Information $(\mathrm{N}=146)$

\begin{tabular}{|l|l|l|}
\hline Demographics & Frequency & Percentage \% \\
\hline Gender & & \\
\hline Male & 61 & 41.8 \\
\hline Female & 85 & 58.2 \\
\hline Total & $\mathbf{1 4 6}$ & $\mathbf{1 0 0}$ \\
\hline Level/Year of Study & & \\
\hline 300 Level (Year Three) & 75 & 53.19 \\
\hline 400 Level (Year Four) & 71 & 48.63 \\
\hline & & \\
\hline Total & $\mathbf{1 4 6}$ & $\mathbf{1 0 0 . 0}$ \\
\hline Age & & \\
\hline $21-25$ years & 105 & 71.92 \\
\hline $26-30$ years & 37 & 25.34 \\
\hline 31 years + & 4 & 2.74 \\
\hline & & \\
\hline Total & $\mathbf{1 4 6}$ & $\mathbf{1 0 0}$ \\
\hline
\end{tabular}

\section{DATA ANALYSIS RESULTS}

Descriptive statistics including percentages and frequency count together with Friedman Test were used for the analysis of data. The results obtained are presented as follows:

The demographic information of respondents who took part in the study in Table 1 reveals that more male than female took part in the study. Moreover, the demographic information on the respondents' levels (Year) of study reveals that respondents in year three of the study constituted the majority compare to their counterpart in year four of study. As mentioned earlier in the methodology, respondents were drawn from among the year 3 and 4 students. The reason being that they had offered courses on online information retrieval and information gathering, so; they know much about what web searching and its effectiveness entail. In addition, the study indicate that majority of the respondents fall between the ages of 21-25years while the represented are those in their 31 years of age and above (Table 2).

The inter-correlation between the independent variables (web search effectiveness) and the independent variables (Internet self-efficacy, computer self-efficacy, Information Literacy Skills, Use of Boolean Operators, Use of Appropriate Search Terms and Web Search Effectiveness) showed that significant inter-correlation exist among the variables. The results show that the entire web search effectiveness variables identified in this study significantly correlated with Web search effectiveness. To establish the joint prediction of the factor and contribution of each to the prediction of web search effectiveness, a multiple regression analysis was conducted. The result is presented as follows.

Table 3 suggests that the $\mathrm{R}$ square $=0.61, \mathrm{R}$ value adjusted $=0.53$, and the overall correlation of all the web search effectiveness determinants yielded an $\mathrm{R}=0.43$, while the standard error of the estimate yielded 531. In the second step, the analysis of variance performed on multiple regressions yielded an F-ratio value of 17.47. This was found to be significant at 0.05 levels. These results suggest that all the four web search effectiveness factors together made $61 \%$ of web search effectiveness. This suggests that all the five factors jointly determine web search effectiveness. 
Table 2. Inter-Correlation Matrix among the Variables ( $\mathrm{N}=146)$

\begin{tabular}{|l|l|l|l|l|l|l|}
\hline $\begin{array}{l}\text { Determinants of Web } \\
\text { Search Effectiveness }\end{array}$ & $\begin{array}{l}\text { Internet } \\
\text { Self- } \\
\text { Efficacy }\end{array}$ & $\begin{array}{l}\text { Computer } \\
\text { Self- } \\
\text { Efficacy }\end{array}$ & $\begin{array}{l}\text { Information } \\
\text { Literacy } \\
\text { Skills }\end{array}$ & $\begin{array}{l}\text { Use of } \\
\text { Boolean } \\
\text { Operators }\end{array}$ & $\begin{array}{l}\text { Use of } \\
\text { Appropriate } \\
\text { Search } \\
\text { Terms }\end{array}$ & $\begin{array}{l}\text { Web Search } \\
\text { Effectiveness }\end{array}$ \\
\hline Internet Self-Efficacy & 1000 & 1000 & 1000 & 1000 & 1000 & 1.000 \\
Computer Self-Efficacy & $0.115^{*}$ & $0.211^{*}$ & $0.121^{*}$ & $0.234^{*}$ & $0.421^{*}$ & \\
Information Literacy Skills & 0.076 & 0.023 & $0.176^{*}$ & $0.702^{*}$ & & \\
Use of Boolean Operators & 0.062 & 0.0199 & $0.761^{*}$ & & & \\
Use of Appropriate Search & 0.008 & $0.889^{*}$ & & & & \\
Terms & $0.871^{*}$ & & & & & \\
Web Search Effectiveness & & & &
\end{tabular}

${ }^{* *}$ Correlation is significant at the 0.05 level (2-tailed).

\section{Table 3. Model Summary}

\section{Multiple R .434 \\ R Square .611 \\ Adjusted R Square .531}

Std. Error of the Estimate $\mathbf{. 7 3 5 4 9}$

Log-likelihood Function Value -362.211

\begin{tabular}{|l|l|l|l|l|l|}
\hline ANOVA & Sum of Squares & Df & Mean Square & F & Sig. \\
\hline Regression & 213316.327 & 4 & $\mathbf{5 3 , 3 2 9}$ & 17.47 & .185 \\
Residual & $\mathbf{4 3 1 8 9 2 . 3 5 1}$ & 141 & $\mathbf{3 , 0 5 3 . 1}$ & & \\
Total & $\mathbf{6 4 5 , 2 0 8 . 6 7 8}$ & 145 & & & \\
\hline
\end{tabular}

Table 4 above demonstrates that each of the five independent variables made a significant determinant of web search effectiveness. In terms of the magnitude, Internet self-efficacy made the most significant contribution with (Beta, $.653, \mathrm{t}=3.789$ ), followed by Information Literacy Skills with $($ Beta $=0.532, \mathrm{t}=.1 .286)$. The next contributing value was exerted by Use of Boolean Operators with $($ Beta $=0.427, t=1.112$; followed by Use of Appropriate Search Terms with $($ Beta $=0.416, t$

Table 4. Coefficients of the Contribution of each factor

\begin{tabular}{|c|c|c|c|c|c|c|}
\hline & \multicolumn{2}{|c|}{$\begin{array}{l}\text { Unstandardized } \\
\text { Coefficients }\end{array}$} & \multicolumn{2}{|c|}{$\begin{array}{l}\text { Standardized } \\
\text { Coefficients }\end{array}$} & \multirow[t]{2}{*}{$\mathbf{T}$} & \multirow[t]{2}{*}{ Sig. } \\
\hline & B & Std. Error & Beta & Std. Error & & \\
\hline $\begin{array}{l}\text { (Constant) } \\
\text { ISE } \\
\text { CSE } \\
\text { ILS } \\
\text { UBO } \\
\text { UAST }\end{array}$ & $\begin{array}{l}16.777 \\
.072 \\
.456 \\
.421 \\
.356 \\
.562\end{array}$ & $\begin{array}{l}3.452 \\
.205 \\
.222 \\
.114 \\
.176\end{array}$ & $\begin{array}{l}.653 \\
.412 \\
.532 \\
.427 \\
.416\end{array}$ & $\begin{array}{l}.087 \\
.085 \\
.078 \\
.066 \\
.045\end{array}$ & \begin{tabular}{l|}
7.542 \\
3.789 \\
.411 \\
1.286 \\
1.112 \\
2.257
\end{tabular} & $\begin{array}{l}.000 \\
.334 \\
.012 \\
.999 \\
.005 \\
.651\end{array}$ \\
\hline
\end{tabular}

Key: ISE - Internet Self-efficacy

CSE - Computer Self- efficacy

ILS - Information Literacy Skills

UBO - Use of Boolean Operators

UAST- Use of Appropriate Search Terms 
Table 5. Relationship among variable Paired Samples Statistics ( $N=146)$

\begin{tabular}{|c|c|c|c|c|}
\hline Paired Variables & Mean & $\mathbf{N}$ & Std. Deviation & Correlation \\
\hline Internet Self-efficacy and & 20.34 & 146 & 10.22 & $0.789 * *$ \\
\hline Web Search Effectiveness & 18.44 & 146 & 9.33 & $0.411 * *$ \\
\hline Computer Self-efficacy and & 18.34 & 146 & 8.43 & $0.286 * *$ \\
\hline Web search effectiveness & 18.11 & 146 & 8.12 & $0.112 * *$ \\
\hline Information Literacy Skills and & 18.02 & 146 & 8.01 & $0.257 * *$ \\
\hline Web search effectiveness & & & & \\
\hline Use of Boolean Operators and & & & & \\
\hline Web search effectiveness & & & & \\
\hline Use of Appropriate Search & & & & \\
\hline Terms and Web search & & & & \\
\hline effectiveness & & & & \\
\hline
\end{tabular}

$=.2 .257)$ while Computer Self-Efficacy made the least contribution with $($ Beta $=0.412 ; \mathrm{t}=0.411)$. This suggests that all the factors are good determinants of web search effectiveness.

\section{Significant Correlation**}

The results in Table 5 above suggest all the constructs significantly correlate with users' web search effectiveness. This answer research questions 1 . The results also revealed the mean and standard deviation for each of the independent variables.

\section{Discussion of Findings}

This study has examined an empirical analysis of the determinants of library and information science students' web search effectiveness at the University of Ilorin, Nigeria. The findings of the study have revealed that internet self-efficacy, computer self-efficacy, information literacy skills, use of Boolean operators, and use of appropriate search terms significantly correlate with web search effectiveness. Similarly, the results suggest that all the five factors jointly determine web search effectiveness. In order of magnitude of the prediction, internet self-efficacy exerted the most significant determinant/ prediction of web search effectiveness followed by information literacy skills, use of Boolean operators, use of Appropriate Search Terms while computer self-efficacy was the least determinant of web search effectiveness.

The results that Internet self-efficacy, information literacy skills, use of Boolean operators and appropriate search terms together with computer self-efficacy determine web search effectiveness is in accordance with Tella et al (2017) report; that, interaction effect exist between internet selfefficacy, and use of Boolean search operators and that the factors significantly correlate with and predict information retrieval effectiveness. The determinant capability of factors like internet selfefficacy to web search effectiveness should not be co-incidence. This is because being internet selfefficacious will go a long way to assist ones' search activities on the net and undoubtedly that will result to search effectiveness. The result could also be based on the knowledge of the courses such as online information gathering and online information retrieval which the respondents in this study have offered as parts of their bachelor's degree subjects or courses. It is possible that the knowledge and experience in those courses come to play in this study and the consequence is the effectiveness in the search activities of the respondents.

Similar findings by Papasratorn and Wangpipatwong (2006) suggested that computer self-efficacy is an important determinant of outcomes. The outcomes in this study could be referred to the search outcomes. Meaning that a searcher who is computer self-efficacious or computer literate will always achieve positive outcomes in terms of having the outcomes of his/her search activity to be effective. Therefore; students with low computer self-efficacy may feel uncomfortable, thereby affecting the expected outcomes. Boverie et al (1998) also found something similar by reporting that; as students 
became more computer self- efficacious, the more satisfied they were with an online information retrieval. Just like the internet self-efficacy. It is assumed that good knowledge of computer will affect the search activities on the internet and good internet self-efficacy will also affect the search through the web.

The rationale behind information literacy taught at the undergraduate and graduate level is for them to be able to know when information is needed, how to search for such information, and how to use and apply such information to make certain decisions and solve information need problems. Not surprising therefore that this factor relates with and determine web search effectiveness in this study. Adequate information literacy skills will no doubt results in development of good information search skills and the eventuality is effectiveness in search activity anytime and anywhere on the web. As the individual already have the skills and experience of how to long on to the internet/web; therefore, searching would not be a difficult task to perform.

The correlation of the use of Boolean operators and its contribution to web search effectiveness is also not a co-incidence. Using Boolean operators in search activity enable the searcher to get relevant and useful information that satisfy his/her needs. In the light of this, it is generally assumed that the proper use of query operators would increase the effectiveness of Web searches. This provide credence to finding in this study. Similarly, the report that retrieval effectiveness was associated positively with best-match searching and Use of Boolean operators in Web queries (Ford, Miller, Moss, 2002) and Upstate Library (2018) corroborate the present finding in this study. Similarly, this study reveals that use of appropriate search terms positively correlate with and determine web search effectiveness. This is in consonant with the position by Victor Valey College (2018) who indicated that the key to engage in an effective web search is to use appropriate search terms and techniques that can be applied to most web search. In furtherance to this, Marchionni.; Dwiggins; Katz; Lin (1993) as earlier claimed that use of appropriate search terms enables quick retrieval of relevant information without having to shift through thousands of unrelated links.

\section{CONCLUSION}

As evident from this study, extant literature has revealed that the effect of psychological and technological along with social elements has not been extensively investigated. This may be responsible for the limited findings from the previous studies to back up the findings in this study. This shows clearly that much has not been done in the areas of examining factors like internet and computer selfefficacy, information literacy skills, use of Boolean operators and appropriate search terms as they affect web search effectiveness. This is considered one of the contributions of this study to knowledge.

\section{Recommendations and Future Research Directions}

This study has demonstrated that factors such as internet and computer self-efficacy, information literacy skills, use of Boolean operators and appropriate search terms significantly correlate with and capable of determining web search effectiveness. In the light of this, this study recommends that LIS students need to be more internet and computer self-efficacious so that their web search activities will always yield positive results. They can engage themselves in self-efficacy, computer and information training to further improve their skills of searching information on the web. Moreover, enrolling for more training on the use of Boolean operators and appropriate search will also go a long way to assist the students. The experience is assumed to enhance and facilitate their search activities.

Future research needs to examine the relationship between individual characteristics and other variables such as domain knowledge of subject that might have an important effect on web search effectiveness. Future research should strive to develop a specific measure that can successfully determine web search effectiveness. It should be noted that this study focused only on undergraduate library and information science students in year three and four from the researcher's university. This is considered a limitation in view of the numerous universities and various categories of undergraduate 
students in Nigeria. In the light of this, it is recommended for the future researcher to consider extending the study to cover more universities and different categories of students. This will enable comparison of web search effectiveness base on discipline and field of study and as well determine who search better than the other base on discipline, knowledge of Boolean operators, information literacy skills, internet and computer self-efficacy and other variables that may be included. 


\section{REFERENCES}

Alhenshiri, A., \& Duffy, J. (2010). User Studies in Web Information Retrieval: User-Centered Measures in Web IR Evaluation. Paper presented at the IEEE 24th International Conference on Advanced Information Networking and Applications Workshops (WAINA), Perth, WA, Australia. doi:10.1109/WAINA.2010.135

Association of College and Research Libraries (ACRL). (2000). Information literacy competency standards for higher education. Chicago: Association of College and Research Libraries. Accessed February 10, 2018. http// www.acrl.org/ala.mgrps/divs/acrl/stndards/standards.pdf

Babbie, E. (2014). The Practice of Social Research (10th ed.). Thomson/Wadsworth.

Bates, M. J. (2007). What is browsing - really? A model drawing from behavioural science research. Information Research, 12(4). Retrieved May 10, 2017, from http://InformationR.net/ir/12-4/paper330.html

Booth, A. (2016). Searching for qualitative research for inclusion in systematic reviews: A structured methodological review. Systematic Reviews, 5(1), 74. doi:10.1186/s13643-016-0249-x PMID:27145932

Borgman, C. (1996). Why are Online Catalogs Still Hard to Use? Journal of the American Society for Information Science, 47(7), 493-503. doi:10.1002/(SICI)1097-4571(199607)47:7<493::AID-ASI3>3.0.CO;2-P

Boverie, P., Nagel, L., McGree, M., \& Garcia, S. (1998). Predictors of satisfaction for distance learners: A study of variable conditions. Outlook, 26(2), 2-7. doi:10.1145/281083.281086

Cassidy, S., \& Eachus, P. (1999). Learning style, Academic Belief Systems, Self-Report Student Proficiency and Academic Achievement in Higher Education. Proceedings of the 4th Annual Conference of the European Learning Styles Information Network, 125-140.

Cassidy, S., \& Eachus, P. (2002). Developing the computer user self-efficacy (CUSE) scale: Investigating the relationship between computer self-efficacy, gender and experience with computers. Journal of Educational Computing Research, 26(2), 169-189. doi:10.2190/JGJR-0KVL-HRF7-GCNV

Chinyere, E. U. (2014). Effects of library instruction on satisfaction with the use of library and its services: A study of undergraduate students in five universities in the Southern part of Nigeria. European Scientific Journal, 10(13), 1857-7881.

Collins, J. (2018). What Does Boolean Search Really Mean? Accessed May 10, 2018. https://www.lifewire. com/what-does-boolean-search-3481475

Compeau, D. R., Higgins, C. A., \& Huff, S. (1999). Social Cognitive Theory and Individual Reactions to Computing Technology: A Longitudinal Study. Management Information Systems Quarterly, 23(2), $145-158$. doi: $10.2307 / 249749$

Creswell, J. (2014). A Concise Introduction to Mixed Methods Research (Sage Mixed Methods Research). Sage Publications, Inc.

Eastman, C. M., \& Jansen, B. J. (2004). The Appropriate (and Inappropriate) Use of Query Operators and Their Effect on Web Search Results. Proceedings of 274 the 67 ${ }^{\text {th }}$ ASIS \& T Annual Meeting, 41, 274-279.

Florida Community College. (2018). LIS2004: Web Search Engines. https://irsc.libguides.com/c. $\mathrm{php} ? \mathrm{~g}=146743 \& \mathrm{p}=963137$

Ford, N., Miller, D., \& Moss, N. (2002). Web search strategies and retrieval effectiveness: An empirical study. The Journal of Documentation, 58(1), 30-48. doi:10.1108/00220410210425395

Ford, N., Miller, D., \& Moss, N. (2005). Web search strategies and human individual differences: Cognitive and demographic factors, Internet attitudes, and approaches: Research Articles. Journal of the American Society for Information Science and Technology, 56(7), 741-756. doi:10.1002/asi.20168

Hölscher, C., \& Strube, G. (2000). Web search behaviour of internet experts and newbies. International Journal of Computer and Telecommunications Networking, 33(1\&6), 337-346. doi:10.1016/S1389-1286(00)00031-1

Howard, H. (1982). Measures that discriminate among online users with different training and experience. Online Review, 6(4), 315-326. 10.1108/eb024106 
Khan, B. S., \& Muaz, A. N. (2018). Emerging topics in Internet technology: A complex networks approach. Internet Technology Letters, 1(4), e41. Advance online publication. doi:10.1002/itl2.41

Kim, K. S. (2008). Effects of emotion control and task on Web searching behaviour. Information Processing \& Management, 44(1), 373-385. doi:10.1016/j.ipm.2006.11.008

Knight, S. A., \& Spink, A. H. (2008). Toward a web search information behavior model. In A. Spink \& M. Zimmer (Eds.), Web Search (pp. 209-234). Springer. doi:10.1007/978-3-540-75829-7_12

Lewandoski, D. (2008). The retrieval effectiveness of web search engines: Considering results descriptions. The Journal of Documentation, 64(6), 914-937. doi:10.1108/00220410810912451

Lewandoski, D. (2015). Evaluating the retrieval effectiveness of web search engines using a representative query sample. Journal of the American Society for Information Science and Technology, 66(9), 1763-1775. Advance online publication. doi:10.1002/asi.23304

Lopes, A. G. (2016). Using research methods in human computer interaction to design technology for resilience. Journal of Information Systems and Technology Management, 13(3), 363-388. doi:10.4301/S180717752016000300001

Malik, A., \& Mahmood, K. (2009). Web search behaviour of university students: a case study at University of the Punjab. Webology, 6(2). Accessed May 10, 2018. From http://www.webology.ir/2009/v6n2/a70.html

Marchionini, G., Dwiggins, S., Katz, A., \& Lin, X. (1993). Information seeking in full-text end-user-oriented search-systems. The roles of domain and search expertise. Library and. Information Science Research, 15(1), 35-69. https://eric.ed.gov/?id=EJ461568

Martzoukou, K. (2005). A review of Web information seeking research: considerations of method and foci of interest. Information Research, 10(2). http://InformationR.net/ir/10-2/paper215.html]

Moon, B.J. (2004). Consumer adoption of the internet as an information search and product purchase channel: some research hypotheses. International Journal of Internet Marketing and Advertising, 1(1), 104-118.

Naughton, J. (2016). The evolution of the Internet: From military experiment to general purpose technology. Journal of Cyber Policy, 1(1), 5-28. doi:10.1080/23738871.2016.1157619

Olaniyi, O. T. (2018). Information literacy for the pre-service teachers. Technical Press.

Papasratorn, B., \& Wangpipatwong, T. (2006). The Effects of Self-efficacy and Attitude on E-learning Outcomes. In T. Reeves \& S. Yamashita (Eds.), Proceedings of E-Learn 2006--World Conference on E-Learning in Corporate, Government, Healthcare, and Higher Education (pp. 2264-2270). Honolulu, HI: Association for the Advancement of Computing in Education (AACE). Retrieved October 20, 2019 from https://www.learntechlib. org/primary/p/24047/

Rice, R. E., McCreadie, M., \& Chang, S. L. (2001). Accessing and browsing information and communication. MIT Press. doi:10.7551/mitpress/1066.001.0001

Russel-Rose, T. (2011). Designing the search experience. In P. Campos, N. Graham, J. Jorge, N. Nunes, P. Palanque, \& M. Wincler (Eds.), Human-Computer Interaction - Interact. Lecture Notes in Science, 6949. Springer. doi:10.1007/978-3-642-23768-3_123

Russell-Rose, T., \& Chamberlain, J. (2017). Expert search strategies: The information retrieval practices of healthcare information professionals. JMIR Medical Informatics, 5(4), e33. Retrieved May 10, 2018, from. doi:10.2196/medinform.7680 PMID:28970190

Spink, Jansen, Wolfram, \& Saracevic. (2002). From E-sex to E-commerce: Web Search Changes. IEEE Computer, 35, 107-111. 10.1109/2.989940

Spink, A., \& Jansen, B. J. (2004). A study of Web search trends. Webology, 1(2). Accessed May 10, 2018. http:// www.webology.ir/2004/v1n2/a4.html

Syamalamba, R. (2011). Information Literacy Programmes for Undergraduate Students. International Journal of Digital Library Services, 1(1), 49-61. digitalcommons.unl.edu/libphilprac 
Tella, Anyim, Memudu, \& Olaniyi. (2017). Predictors of information retrieval effectiveness among library and information science undergraduates in Kwara state universities. Library Philosophy and Practice (e-journal). 1626. Accessed May 10, 2018. https://digitalcommons.unl.edu/libphilprac/1626

Tella, A. (2011). An assessment of mathematics teachers' self-efficacy: implication on teachers' delivery of mathematics instruction. International Journal of Mathematics Education in Science and Technology, 42(2), 155-174. 10.1080/0020739X.2010.519798

Tella, A. (2011). Predictors of undergraduate students' web search effectiveness. International Journal of Information Studies, 3(3), 95-105.

Tella, A. (2013). Predictors of Library and Information Science Undergraduates' Participation in Online Discussion Forum. College and Undergraduate Libraries, 20(2), 156-172. . 10.1080/10691316.2013.789668

Tella, A. (2014). Information literacy and lifelong learning: A review of literature. In J. S. Keengwe (Ed.). Advances in Higher Education and Professional Development. IGI Global Publisher.

Tella, A., Oyewole, M., \& Tella, A. (2017). An analysis of perceived usefulness of Google Scholar by the postgraduate students of the University of Ilorin, Nigeria. South Africa Journal of Information Management, 19(1). . 10.4102/sajim.v19i1.793

Tella, A., \& Oladapo, O. J. (2016). A comparative analysis of available features and Web 2.0 tools in selected Nigerian and South African university library websites. The Electronic Library, 34(3), 504-521. doi:10.1108/ EL-10-2014-0182

Tella, A., \& Oyedokun, T. T. (2014). An Evaluation of Online Reference Services Through Social Networking Sites in Selected Nigerian University Libraries. The Reference Librarian, 55(4), 343-347. doi:10.1080/02763 877.2014.947889

Upstate Library. (2018). Effective Searching: Effective searching tips \& tools. Accessed May 10, 2018. https:// uscupstate.libguides.com/c.php?g=257849\&p=1722200

Victor Valley College. (2018). What is Boolean operators? Accessed May 10, 2018. https://library.vvc.edu/ welcome/boolean

Wolfinbarger, M., Gilly, M. C., \& Schau, H. J. (2005). Keeping up with the times: Innovation and usage of the Internet among later adopters. CRITO Consortium Project. Accessed May 10, 2018. www.crito.uci.edu/ consortium

Xie, I. (2010). Information Searching and Search Models. Encyclopedia of Library and Information Sciences (3rd ed.). Taylor \& Francis. doi:10.1081/E-ELIS3-120043745

Zhang, X., Anghelescu, H. G. B., \& Yuan, X. (2005). Domain knowledge, search behaviour, and search effectiveness of engineering and science students: An exploratory study. Information Research, 10(2). Retrieved May 10, 2018, from http://InformationR.net/ir/10-2/paper217.html

Adeyinka Tella is a researcher who loves researching and publishing papers in high impact journals.

Saheed Oyeniran (PhD) is Lecturer in the Department of Educational Management, Faculty of Education, University of Ilorin, Nigeria.

Ibironke Ebenezer Sanya is a lecturer in the Department of Educational Technology, University of Ilorin, Nigeria. 